Boise State University

ScholarWorks

Political Science Faculty Publications and

Presentations

Department of Political Science

$10-1-2008$

Regional Cooperation in Employment and Training Policy: A Matter of Collective Action or Intergovernmental Relations?

Susan G. Mason

Boise State University 


\title{
Regional Cooperation in Employment and Training Policy: A Matter of Collective Action or Intergovernmental Relations?
}

\author{
Abstract \\ This article provides empirical evidence that factors derived from the collective action theories \\ resonated with employment and training policy implementers as the most influential for \\ achieving regional cooperation for community development. Findings indicate that having \\ specific reasons and the opportunity to benefit from collaborating does more to advance \\ cooperation than competing for scarce resources. Permitting Workforce Investment Boards self- \\ governing authority and providing an opportunity for mutual gains are promising means for \\ gaining substantive cooperation both within and across workforce investment areas in U.S. \\ employment and training policy.
}

Keywords: Regional Cooperation; Employment and Training; and Policy Implementation 


\section{Regional Cooperation in Employment and Training Policy: A Matter of Collective Action or Intergovernmental Relations?}

Global competition is making regional economic cooperation a more meaningful policy for community development. As markets integrate regionally and globalize internationally cooperation in economic development is becoming increasingly important. One prominent feature of globalization is the value of cooperation among an increasing number of players to continue economic growth. In the United States there is great potential benefit for regional cooperation in employment and training policy. Employment and training policy tries to enhance individuals' skills and connect people with marketable jobs in their communities. The most recent employment and training policy, the Workforce Investment Act (WIA) of 1998, asks a wide variety of organizations to cooperate to meet the labor demands within economic regions. Additionally, WIA recommends that workforce investment board (WIB) areas that are contained within the same economic region cooperate across their borders. ${ }^{1}$

This study examines cooperation in U.S. regions that are integrated economically but not politically in both intra- and interstate metropolitan areas. Factors that policy implementers see as most important to cooperation are identified. Examining employment and training policy from the perspective of economic regions is salient because economic and employment problems typically ignore the local governments boundaries that make up intergovernmental relations in communities (Barnes \& Ledebur,1998; Wright, 1988). Implementing employment and training policy regionally may mitigate some of the competitive factors communities in metropolitan areas face when both business and labor are mobile.

Only a few studies have made use of empirical evidence to further our understanding about cooperation in economic regions, especially those that are interstate. Zimmerman specifically notes that interstate cooperation is an area that researchers have paid relatively little 
This is an electronic version of an article published in Journal of the Community Development Society 39(4): 1-16. Journal of the Community Development Society is available online at: http://www.informaworld.com/smpp. DOI: 10.1080/15575330809489655

attention (2002). Those case studies that do measure or quantify their evidence for cooperation treat it as voluntary rather than requested by a higher authority. Studies that do provide empirical evidence for voluntary cooperation include Perkmann's work on regional cooperation across borders in Europe (2003), Olberding's evidence on voluntary regional partnerships in economic development (2002a; 2002b) and Lackey, Freshwater and Rupasingha's examination of cooperation in rural areas in Tennessee (2002). Yet, cooperation is not always voluntary. In fact, U.S. policy mandates cooperation in public policy areas such as homeland security and employment and training policy. Subsequently WIA, the most recent employment and training policy, is a particularly good test case for understanding more about economic regional cooperation across communities for three reasons: 1) U.S. employment and training policies have historically been rife with a lack of cooperation and coordination; 2) WIA requires 17 programs to cooperate which is a wider variety than any previous employment and training policy; and 3) this federal policy encourages U.S. states to cooperate when they share a stake in the performance of economic regions that extend across state borders or are contained within a state. $^{2}$

Much of our understanding of the factors that affect cooperation in the U.S. has been developed through case studies from intergovernmental relations (IGR)and public policy implementation literature (Wright, 1998; Zimmerman, 2002; Oakerson, 1987; Kenyon, 1999; Mazmanian \& Sabatier, 1983; and Pressman, 1975) as well as the collective action literature on common pool resources (Ostrom, 1990; Singleton, 1998). ${ }^{3}$ Since cooperation is not always voluntary, the collective action literature is particularly attractive theoretical lens to use for understanding regional cooperation in employment and training policy. What is lacking is a clear understanding of the way the IGR and collection action theories can foster cooperation in 
implementing public policy. The empirical research presented here probes the answers to some basic questions that influence cooperation. What factors from either literature are most important for gaining cooperation? Under which circumstances are the theories important (i.e., interstate or intra-state cooperation)? Is the collective action literature more relevant when the needed cooperation is in regions that cross multiple jurisdictions? Are there best practices or examples of implementation that demonstrate the empirical findings? Drawing from these literatures and informed by 84 interviews with state and regional employment and training experts survey questions were developed. The survey questions provide an empirical assessment of the most important theories that can lead to cooperation by communities in intra- and interstate regions with an empirical assessment of the most important factors. The interviews also help identify best practices or examples that illustrate the way the empirical data on the theories plays out in the community.

\section{TWO LITERATURES ON FACTORS INFLUENCING COOPERATION}

\section{Intergovernmental Relations}

The IGR literature is a useful starting point for understanding cooperation that crosses jurisdictions. It suggests several factors that are important for cooperation. First, state and local jurisdictions and boundaries create complex relationships because of the overlapping political, fiscal, and administrative responsibilities of the governing entities (Wright, 1988, p. 333). This can harm policy cooperation because each jurisdiction has the autonomy to make decisions within its area of authority but they may not have to take into account the effect it has on neighboring jurisdictions or the opportunity that working together might bring to the area. Political Scientist Susan E. Clarke found jurisdictions and responsibilities in workforce development in Denver could indeed hamper cooperation and change. She found that: 
"In Denver, workforce development often appeared to elicit conflicts between functional and territorial interests- a focus on workforce development processes colliding with a territorial focus on poor neighborhoods...To the extent that federal and foundation workforce development monies seemed to repeat funding patterns to the same territorial interests, they signaled a continuation of the "old ways of thinking" to some business interests (Clarke 2002, 14).

Second, this literature indicates there are basic conditions for cooperation that influence policy outcomes. These include the perceived sense of urgency about the problem, the anticipation of low financial or legal costs for the primary participants, and provision of information, technical and financial support (Wright, pp. 397-398). Each of these conditions is relevant to both intra- and interstate cooperation in employment and training policy. The Wage Record Interchange System, (WRIS), is evidence that information facilitates interstate cooperation. WRIS is an interstate clearinghouse for unemployment insurance wage records. The wage record information provided by WRIS helps workforce areas accurately calculate the federally mandated performance outcome that use wage data. Specifically, WRIS provides workforce investment areas data on clients that use services in one state but work in another. The growth in the number of participating states, from seven in 2002 to 40 states in 2003, is undeniable evidence of the value of cooperation and sharing information under WIA (U.S. General Accounting Office 2002, 20; Workforce ATM 2003).

The literature also notes the potential impact that the political image of the participants as well as the pursuit of different goals can have on cooperation. Wright contends "image" refers to the perceptions that local officials have of other IGR participants that help them by reducing the uncertainty involved in interacting (Wright, p. 243) or "the subjective level of confidence with which each decision is made" (Downs, 1967, p. 76). ${ }^{4}$ A potential example from WIA includes 
the willingness of organizations to share resources in a "one-stop" based on the reputation of the other participants even if they had not worked together previously. ${ }^{5}$

Finally, the IGR literature indicates that the pursuit of different goals impedes cooperation. This occurs when two sets of actors are working on a matter but are unaware of or unsympathetic to the other actor's goals (Pressman; Wright). The pursuit of different goals can be illustrated by the fact that some actors involved in WIA are focused on the provision of social services while others have a primary focus on economic development. This results in one agency focusing on the provision of childcare or transportation to foster employability while another agency focuses on training to meet employer needs. This results in different means, objectives, and goals for the actors' work. To this point, one state official noted that there is "tension between those who look at [WIA] as written for the poorer people and those who see the [WIA] as a broader system.",6

There are also instances of personal animosity in the intergovernmental relationship and this might be elicited by questioning the motives or intentions of others (Wright, 246). An example from one interview that brings this theory home follows. When asked about what factors keep stakeholders from cooperating to make workforce development effective the interviewee noted, "We have not worked together before and in some places it is old relationships that go back to whether or not there should be red light or a stop sign. I am not kidding. They haven't worked together since. It's colloquial but it matters."

\section{Collective Action}

The collective action literature examines general theories and hypotheses about cooperation among individuals, associations, agencies, and governments and provides perhaps the best 
opportunity to understand cooperation in employment and training policy. It is particularly helpful in two ways. First, collective action resolves problems that a single individual cannot solve alone. The traditional explanation of collective action problems is that they occur when a lack of cooperation prevents a mutually beneficial outcome (Singleton, 1998). Second, the collective action literature describes circumstances that inhibit cooperation such as free-rider problems and transaction costs. This literature also suggests several mechanisms for overcoming collective action problems and improving cooperation such as social institutions and self governing authority.

The free-rider problem occurs when people can benefit from the production of a good or service without contributing to the cost of its production (Sandler, 1992). A potential example of the free-rider problem in employment and training policy could occur if one business provides job training and then another business later hires the trained employee without having contributed to the training. The free-rider problem may translate to agencies or employers being reluctant to participate in WIA because of concerns that the benefits of their efforts are serving non-participating or non-paying businesses. Agencies or institutions may also be affected by free-rider problems if, for the purpose of meeting performance measures, they cannot claim the credit for the individuals they help.

Transaction costs are the resources devoted to measurement and enforcement of agreements (North, 1990) as well as the resources expended for negotiating possible solutions (Singleton, 1998). Under the Manpower and Development Training Act of 1965 the Labor Department contracted out to at least 10,000 private businesses, non-profit and community based organizations, and state and local agencies to provide employment and training services. Ultimately, the employment training system became too complicated and fragmented for the 
This is an electronic version of an article published in Journal of the Community Development Society 39(4): 1-16. Journal of the Community Development Society is available online at: http://www.informaworld.com/smpp. DOI: 10.1080/15575330809489655

institutional arrangements to operate efficiently making the transaction costs too high. Another example of the effects of transaction costs is the concern employment and training providers have about the cost of collecting information required under WIA. Interviews conducted for this research with policy experts revealed that the burden of gathering and reporting this information has been a factor in training providers' reluctance to participate in the program.

The role that social institutions play is one of the most helpful insights of the collective action literature for explaining cooperation in employment and training policy. Knight reveals that social institutions can be simple structures such as a neighborhood organization or more complex institutions such as economic organizations and multi-national corporations. These institutions foster cooperation by providing information that resolves uncertainty and stabilizes expectations between participants. Additionally, institutions are helpful for obtaining mutually beneficial outcomes because they provide maintenance and stability in the distribution of outcomes so that the outcomes do not exclusively favor any one group (1992). By performing this function, institutions become the arrangements that provide the opportunity to reduce transaction costs and help overcome collective action problems. Social institutions spread the rules and uphold the values that are accepted by the participants.

The authority for self-governing and organizing provides a necessary mechanism for obtaining cooperative behavior with multiple levels of government as well as promotes the efficient use of social institutions. Specifically, it permits members to create their own contracts and thus lowering the transaction costs involved with establishing and monitoring new institutions, reducing free-rider problems, and fostering communication. This leads to more efficient and/or stable institutions that can harness more information and resources than individuals or organizations could do otherwise. The institutions themselves provide incentives 
This is an electronic version of an article published in Journal of the Community Development Society 39(4): 1-16. Journal of the Community Development Society is available online at: http://www.informaworld.com/smpp. DOI: 10.1080/15575330809489655

that foster cooperative behavior as well as a mechanism for overcoming collective action problems. Employment and training policy might also benefit from self-governing and selforganizing authority that could foster local level cooperation in both the intra-state and interstate regions in WIA. This authority might be guided or aided by regional and national bodies.

In light of the discussion presented collective action theories should provide better tools for gaining cooperation under the circumstances as intergovernmental boundaries do not coincide with economic regions. Given the increased likelihood of less voluntary and more mandatory cooperative endeavors do to, in part, the pressures of globalization, climate change and security issues the more collective action literature is likely to offer our communities. The collective action literature stands to provide more in terms of tools for creating healthier and more secure communities both financially and physically.

\section{DATA AND METHODOLOGY}

This analysis uses data compiled from a 2003 survey of all of the individual workforce investment board members in 46 workforce investment areas in the U.S. The survey provides primary data from five interstate regions and four intra-state regions to investigate the aforementioned factors that affect cooperation in employment and training policy. The five interstate regions are Chicago (IL-IN), Cincinnati (OH-KY-IN), Kansas City (MO-IL), Louisville (KY-IN), and St. Louis (MO-IL), and the four intra-state regions are Cleveland (OH), Indianapolis (IN), Peoria (IL), and Springfield (MO). The interstate areas are major metropolitan areas with populations over one million. The intra-state regions are chosen to control for state effects.

\section{Survey Design and Administration}


This is an electronic version of an article published in Journal of the Community Development Society 39(4): 1-16. Journal of the Community Development Society is available online at: http://www.informaworld.com/smpp. DOI: 10.1080/15575330809489655

The survey instrument, created in 2002, uses questions derived from the IGR and collective action literatures as well as factors identified in interviews with policy experts. By design the entire population of the local workforce investment boards was surveyed. Using the entire population reduces bias and sampling error due either investigator discretion or respondent characteristics. Since this study has a population that is just over 1,500 a response rate of 600 yields a plus or minus reliability factor just between three and four percent.

To guard against measurement error, the survey was pre-tested for clarity of the questions and the reliability of responses -- measuring the concepts they were intended to measure-- with seventeen survey takers from the nine metropolitan regions. Some of the changes made from the pre-test included adding questions that directly asked about cooperation and effectiveness. Finally, in March of 2003 the survey was mailed to 1,538 workforce investment board members in nine metropolitan areas using Dillman's (2000) “Total Design Method". The final population of survey respondents was $1,521 .^{7}$ Six hundred and ten completed surveys were returned providing a 40 percent response rate.

The survey recipients were all the members of the 46 workforce boards in the nine metropolitan regions. The board members are charged with oversight and guidance of the implementation of employment and training policy for their workforce investment areas. The workforce boards are comprised of members representing the many sectors that are affected by employment and training policy. At the local level the chief elected official such as a mayor or county executive appoints the board members. A representative from the business sector chairs the workforce investment board. Additionally, business representation is required to be 51 percent of the make-up of the board at both the state and local level. In theory, the business representatives are chief executives because they have the authority to make decisions for their 
This is an electronic version of an article published in Journal of the Community Development Society 39(4): 1-16. Journal of the Community Development Society is available online at: http://www.informaworld.com/smpp. DOI: 10.1080/15575330809489655

organization. In practice, many times the business representative is a senior human resource person from the company she represents. The other sectors represented on the boards include; organized labor, education (primarily but not exclusively post-secondary), economic development, the program agencies involved with the one-stops, community based organizations, government and public officials such as mayors and legislators. Other representatives include constituents from sectors such as health care, child support and TANF, as well as farmers and other people representing community or rural interests. The number of members on the workforce boards in this study ranges in size from 11 to 68 .

The diversity of the respondents approximates the membership of the board, as seen in Table 1. A large majority of respondents (64\%) indicate they were on the board for two years or more. This fact suggests that most of the respondents have substantial experience supporting their comments. The survey items (see Tables 2, 3, and 4) were drawn specifically from the two literatures as well as interviews with policy experts. All questions were on a seven point scale with the exception of four questions that were on a five point scale. Using the mean of the responses on each of the measures provides an overall sense of importance or weight of each factor to the responding practioners. By examining the t-test for each and whether the outcomes are statistically significant provides more weight for the evidence. The factors are also considered in terms of the percentage of responses as agree or strongly agree by board member type and type of region (i.e., intra- or interstate). Additionally, ANOVA analysis was used to identify differences in means by intra and interstate region type as well as differences between groups of board members. ${ }^{8}$ Finally a factor analysis is performed on the 10 potentially motivating factors to cooperation from the IGR literature and the 11 potentially motivating 
This is an electronic version of an article published in Journal of the Community Development Society 39(4): 1-16. Journal of the Community Development Society is available online at: http://www.informaworld.com/smpp. DOI: 10.1080/15575330809489655

factors derived from the Collective Action literature to further understand the theories relevance to cooperation with WIBs under WIA.

[Insert Tables 1 about Here]

\section{FINDINGS}

\section{Descriptive Data}

Findings from this survey of workforce investments board members reveal the collective action theory carries more explanatory weight than IGR theory in this situation. Nonetheless a few of the assertions in IGR literature are important for cooperation for workforce investment board members and t-tests reveals that all the differences are statistically significant and did not occur by chance. Table 2 reveals that the "good reputations of the board members" is the most important factor. The fact that gains in cooperation would reduce financial costs of reaching goals is the second most important factor promoting cooperation. The next two highest scoring factors are the importance of reputations for working with other boards is a sense of urgency about the problem. Finally, having the roles and responsibilities of each party clearly defined also appears to be a factor that merits attention for obtaining cooperation by workforce board members. Additionally, at the WIB level, board members personalities are not as important to cooperation as the literature and interviews suggest.

\section{[Insert Table 2 about Here]}

Factors identified in the collective action literature are more relevant to regional cooperation than those found in the IGR literature in employment and training policy. The findings in Table 3 reveal that board members are motivated to cooperate when more individuals and employers are being helped and once again all of the differences are statistically significant. The ability to provide more services was also important for gaining cooperation. Other factors 
that are important for obtaining cooperation are the opportunity to obtain more information, funds via grants, as well as the potential for mutual gains to be realized. The ability to receive credit for outcomes was somewhat less important than the other criteria. Neither the amount of time it takes to reach goals nor the complexity of WIA are considered particularly onerous to achieving cooperation from the descriptive statistics.

\section{[Insert Table 3 about Here]}

Peoria, Illinois provides an example of the way cooperation under WIA was ultized to obtain resources and reduce the financial cost of increasing employment in their region for the benefit of both employers and employees. One interviewee from Peoria recounted that, "Without WIA we would not have the H-1B Grant. ${ }^{9}$ We would have lost that opportunity. The H-1B Grant put 2.5 million into training people on computers-- what we desperately needed. Without WIA the money would have gone elsewhere and we would have had no way to fill our need."

Both literatures identified that processes or the way boards organize themselves can foster cooperation and all but three of the noted findings were statistically significant. Table 4 reveals that the board members score their own boards high on several factors drawn from collective action theories. These factors include boards having the ability to organize their own priorities and having a voice in determining the boards membership. However, workforce boards often indicated that they did not have an institution that was fostering cooperation in their region, an important factor identified in the collective action literature. The mean score for institutions was not different from the theoretical null hypothesis for this factor. The lack of a universally recognized institution to facilitate cooperation may be influencing a low score on communicating frequently with other boards in their region which was also not different from null hypothesis of no effect of communication. In general, board members are noted as bringing 
This is an electronic version of an article published in Journal of the Community Development Society 39(4): 1-16. Journal of the Community Development Society is available online at: http://www.informaworld.com/smpp. DOI: 10.1080/15575330809489655

special interests to the table, a factor that the IGR literature indicates can hamper cooperation.

Yet, at the same time board members are found to be sympathetic to multiple goals which the IGR literature suggests is important for fostering cooperation. Combined, the responses suggest that board members understand the complexity of the issues they are facing when it comes to bringing about cooperation, but may not have all the institutional arrangements in place to achieve their objectives.

An example of the complexity plays out as one interviewee noted in Indianapolis "Marion County is the dominant player and the other areas don't feel they are getting enough attention- resources." He noted that "different priorities" keep stakeholders from cooperating "and when you are talking about different priorities you are also talking about money that people use for priorities and what is viewed as important for economic development and growth." Most of the regional level experts interviewed in Indianapolis saw the regional plan as merely a paper document. However, one interviewee noted that, "Regional planning has helped people recognize the size of stakeholders out of their immediate reality" and another interviewee noted "It has given us a clearer understanding of the different priorities."

Overwhelmingly board members indicate that cooperation between workforce boards is important for improving the workforce development system. Board members did not indicate that competition is important for improving the outcomes and the mean of 3.4 is not different from the null hypothesis of no effect for this factor. Board members were slightly more likely to indicate a top priority of WIA is the provision of social services than they were to indicate economic development. Boards members also see themselves as cooperating and effective within their own boards but they do not report cooperating with other boards to the same degree. [Insert Table 4 about Here] 
This is an electronic version of an article published in Journal of the Community Development Society 39(4): 1-16. Journal of the Community

\section{Analysis by Region Type}

There are clearly key factors that influence cooperation. There may be differences by type of region that could illuminate the circumstances where collective action as opposed intergovernmental relations theory provided more help in achieving cooperation. The same measures that are in Tables 2 through 4 were aggregated to the intra and interstate level to see if there is a spatial difference by type of region. As seen in Table 5 three factors differ in their outcomes by type of region. Personalities are slightly more important in interstate regions than intra-state for gaining cooperation but in neither area are they seen as particularly important. Having a voice is a more important factor in both types of regions but even more so in interstate regions as compared to intra-state regions. The most important factor for both regions is the board's ability to organize their priorities. Once again, this is rated higher by boards in interstate regions compared to boards intra-state regions. Although the differences range only from .3 to .5 between the regions, each factor is seen as more important to interstate regions where presumably there are more impediments to gaining cooperation. Again, the collective action theories more frequently yield relevant information about cooperation when compared to the intergovernmental relations theories.

Two examples of they way having a voice and self-organizing priorities have aided cooperative outcomes are the interstate cases of St. Louis and Cincinnati. St. Louis is an interstate case where the governors of Illinois and Missouri mandated regional planning for implementing the workforce investment in the region. In St. Louis, the East-West Gateway Coordinating Council (the metropolitan planning organization and council of governments) and the St. Louis Regional Chamber \& Growth Association created the Workforce Development Policy Group as a governing taskforce for implementing WIA regionally in response to the 
governors from both states declaring St. Louis a regional workforce area. The Workforce Development Policy Group (WDPG) provides broad direction to the WIBs but has no legal authority. The regional mandate and direction from the WDPG has resulted in the boards standardizing policy manuals, data sharing, and their seeking of interstate agreements, for example. However, the interstate case of Cincinnati demonstrates that having an self-organizing board does not always ensure a high intensity of cooperation, but perhaps some cooperation. In Cincinnati, 13 counties, ten one-stop operators, and the business chamber put together a regional group called Cincinnati U.S.A. Regional One-Stop Consortium. It is unfunded and voluntary and the participants take turns hosting meetings and taking minutes. The consortium began in March 2001. At the local level it is well received but is primarily a vehicle for sharing basic information across jurisdictions rather than an organization for ensuring regional policy implementation.

[Insert Table 5 about Here]

\section{What are the most Salient Factors?}

Factor analysis is one method to test the validity of the concepts tapping into cooperation. Factor analysis is a purely statistical technique that indicates the degree to which factors or items relate to a similar concept (Kim \& Mueller 1978, p. 56). In general there are two uses of factor analysis: exploratory and confirmatory. Exploratory factor analysis permits the research to explore if particular items are related to one another in an atheoretical fashion. For example, if an investigator did not know which personality characteristics where association with a variety of concepts such as being introverted or extroverted, then the investigator could analyze the data using factor analysis and see which characteristics were more closely related to each other.

Factor analysis is a method to test the validity of the constructs where Cronbach's Alpha helps 
This is an electronic version of an article published in Journal of the Community Development Society 39(4): 1-16. Journal of the Community Development Society is available online at: http://www.informaworld.com/smpp. DOI: 10.1080/15575330809489655

determine the reliability measures. Typically a Cronbach's Alpha of .7 or higher demonstrates a very reliable measure of the concept. The IGR and collective action literature provided substantial information about the factors that underlie the concepts of cooperation but how these concepts apply to cooperation under WIA is unknown. Subsequently, exploratory factor analysis is useful to identify which concepts explicitly relate to cooperation with WIBs in WIA.

To determine which factors are most salient for fostering or hindering cooperation the method of factor analysis was employed. Table 6 provides a factor analysis of 10 motivating concepts from the IGR literature and the Cronbach's Alpha for the items. Using Principal Component Analysis (PCA) as the method of extraction it is possible to see which indicators have the most weight when it comes to cooperation with WIBs in WIA. ${ }^{10}$ The Cronbach's Alpha at .59 is acceptable. The eigenvalues for the first three principal components were $2.5,1.5$ and 1.3. Eigenvalues below one are typically discarded as minor factors (Kim and Mueller 1978, p. 9). The varimax rotation provided three factors supporting the cited literature. Together the three factors explain 52 percent of the variance in the original items. The loadings indicate the correlation with the original 10 concepts and are used to label the three salient factors for cooperation from the IGR literature.

The items loading strongly on the first factor, were several items but in light of the combination and following component loadings the results suggest that "defined roles, reduced costs and urgency" are the most beneficial as Wright indicated these to be some of the basic conditions needed for cooperation in intergovernmental relations. The nearly equal loading for the reputation factors in this component suggests that reputation works in concert with roles, urgency and ability to reduce cost. However, the third component "Reputations" highlights the uniquely important role of reputations in and of itself plays for cooperation as both Wright and 
Downs conclude the importance of image or reputation can have and reduce uncertainty which cannot only reduce costs but also enable intergovernmental relations by providing confidence. The second factor is labeled "Personalities and Interests". Although personalities were not deemed vital to cooperation from the descriptive survey data, they did appear more important in interstate regions than intra-state in the analysis by type of region. Findings from interviews in Cleveland, Ohio corroborate that personality or leadership can make a difference as interviews revealed no cooperation between the city of Cleveland and Cuyahoga County however the anticipated change of leadership with a new Mayor of Cleveland has sparked hope for collaboration in the future among interviewees. The factor loadings suggest that in addition to personalities special interests are also important. These findings coincide with Wright, Pressman, Clarke's contention that special interest or different goals are related to obtaining cooperation.

\section{[Insert Table 6 about Here]}

PCA is employed again to determine which concepts from the collective action literature affect cooperation with WIBs under WIA. Table 7 provides the factor analysis of 11 concepts from the collective action literature and the Cronbach's Alpha score for the items. The Cronbach's Alpha is .70 which is considered highly reliable. The eigenvalues generated from the varimax rotation provided four principal factors derived from the collective action literature. The eiginvalues for the four principal components are 3.91, 1.5, 1.12 and 1.0. Together the four factors account for 68 percent of the variance in the original items which is more than 16 percent higher than the IGR factor loadings. The loadings with the original 11 concepts are used to label the four salient factors for cooperation from the collective action theories. 
The items that loaded strongly on the first factor "More Help" all revolve around more people being served whether it be employers or employees. The ability to gain more services and information also fosters cooperation. This supports Singleton's supposition that mutual beneficial outcomes promote cooperation. The second factor "Transaction Costs" play a clear role with time to reach goals and complexity of WIA being rated as high and related to cooperation. The third factor "Self-organizing" and allowing WIBs to have a voice in its membership is also an agent for cooperation as Ostrom, Singleton and other collective action theorist have contended. Finally, the fourth factor "Gains and Credit" indicate mutual gains and the ability to receive credit are also seen as factors that contribute to cooperation under WIA.

[Insert Table 7 about Here]

Efforts in Kansas City, Kansas and Kansas City, Missouri demonstrate they way access to more services, reducing transaction cost, the opportunity to self-organize and the ability to receive credit for outcomes can motivate cooperation. The WIBs in these two communities demonstrate a good working relationship and the ability to establish enabling mechanisms through local agreements to meet employers' needs with the minimum hassle in terms of paper work for the employer. Potential employees may be from either or both Kansas and Missouri training programs that are meeting employer needs because administrators work out the paperwork among themselves so each can obtain due credit and demonstrate accountability for funds.

\section{CONCLUSION}

The data and findings indicate the collective action literature provides more insights into ways to create effective cooperation across communities in employment and training policy. This suggests that regional cooperation in community development is more about collective action 
than intergovernmental relations. Perhaps this is due, in part, to the fact that there are multiple actors that are not directly tied to traditional government sectors. Subsequently, the problems of cooperation are not really confined to intergovernmental actors and actions. Cooperation is motivated by the way communities perceive the potential benefit or gains that will come from boards working together or the potential loss by not doing so.

Information on the way boards operate in employment and training policy reveals that WIA provides an opportunity for boards to exercise a voice and determine their priorities for their communities. Additionally, in each category where the factors are statistically significantly different by region type, the interstate board regions rated these factors as more important than did the intra-state respondents. Board members rate institutions as low in terms of fostering cooperation and at the same time note less cooperation across boards than within boards in communities. The data also reveal that boards clearly see cooperation as important and competition as less important to the success of WIA in their communities.

Isolating specific factors that affect regional cooperation in employment and training policy is helpful for gaining information about cooperation in community development policy. Obtaining mutually beneficial outcomes motivates cooperation in employment and training policy. This suggests that incentives for grants that foster collaboration among boards as well as access to technology or resources could be helpful in achieving cooperative outcomes across communities. The findings also indicate that when cooperation is mandatory, giving boards reasons and rewards for cooperating is the most instructive way to create meaningful cooperation across communities in economic regions. Using punitive measures or placing boards in competition with one another is not nearly as helpful for gaining cooperation. The data also reveal that permitting self-governing authority is conducive to obtaining cooperation. The lower 
rating of cooperation across WIBs as compared to within WIBS is noteworthy. It draws into consideration the potential value of greater institutional participation or oversight could provide for fostering cooperation across communities.

Finally, the factor analysis highlights the ways both literatures can provide useful guiding concepts but even this statistical procedures highlights the a more significant contribution from the collective action literature in terms of percent of variance explained in cooperation as well as the greater number of components generated. Addressing an urgent problem, reducing costs and clearly defined roles are some basic considerations cited in the IGR literature. Personalities and special interests as well reputations of the individuals can play a role in the outcomes as previously noted. The collective action literature illuminates more specifically the way the possibilities to serve more clients and obtain more services and information specifically can foster cooperation. Transaction costs and the ability to self-organize and determine ones own group membership are also key factors. Finally, mutual beneficial outcomes as well the opportunity to claim credit for outcomes are other specific tools that can promote cooperation that are drawn from the collective action literature.

Regional cooperation across jurisdictions is anticipated to be more frequently mandated for the protections of communities in terms of their economic, environmental, and personal security. These findings suggest future research on regional cooperation may find theories derived from the collective action literature to be particularly beneficial to community development. Additional research on the most important factors for obtaining regional cooperation in policy implementation will surely help to improve our economic, environmental, and personal security now and into the future. 


\section{REFERENCES}

Barnes, W. R. \& Ledebur, L.C. (1998) The New Regional Economies: The U.S. Common Market and the Global Economy. Thousand Oaks: Sage Publications.

Clarke, S. E. (2002) "The Politics of Workforce Development: Constructing A Performance Regime in Denver". Paper presented at the Midwest Political Science Association Annual Meeting, Chicago April 2002.

Dillman, D. A. (2000). Mail and Internet Surveys: The Tailored Design Method. (2nd Ed.) New York: John Wiley \& Sons, Inc.

Downs, A. (1967) Inside Bureaucracy. Boston: Little, Brown and Company.

Kenyon, D.A. (1991) Interjurisdictional tax and policy competition: good or bad for the Federal System. U.S. Advisory Commission on Intergovernmental Relations: Washington: D.C., GPO.

Kim, J. \& Mueller, C. W. (1978). Introduction to Factor Analysis: What it is and How to do it. Newbury Park: Sage.

Knight, J. (1992) Institutions and Social Conflict. Cambridge: Cambridge University Press.

Lackey, S. B., Freshwater, D. \& Rupasingha, A. (2002) Factors Influencing Local Government Cooperation in Rural Areas: Evidence From the Tennessee Valley, Economic Development Quarterly. 16(2), 138-154.

Mazmanian, D. A. \& Sabatier, P. A. (1983) Implementation and Public Policy. Glenview: Scott Foresman and Company.

North, D. C. (1999) Institutions, Institutional Change and Economic Performance (Cambridge, Cambridge University Press).

Perkmann, M. (2003) Cross-Border Regions in Europe: Significance and Drivers of Regional Crossborder Co-Operation, European Urban and Regional Studies. 10(2), 153-171.

Pressman, J.L. (1975) Federal Programs and City Politics: The Dynamics of the Aid Process in Oakland. Berkeley: University of California Press.

Oakerson, R. J. (1987) The Organization of Local Public Economies. U.S. Advisory Commission on Intergovernmental Relations: Washington D.C., GPO.

Olberding, J. C. (2002a) Does Regionalism Beget Regionalism? The Relationship Between Norms and Regional Partnerships for Economic Development, Public Administration Review, 62(4), 432-443. 
This is an electronic version of an article published in Journal of the Community Development Society 39(4): 1-16. Journal of the Community Development Society is available online at: http://www.informaworld.com/smpp. DOI: 10.1080/15575330809489655

Olberding, J. D. (2002b) Diving into the "Third Waves" of Regional Governance and Economic Development Strategies: A Study of Regional Partnerships for Economic Development in U.S. Metropolitan Areas, Economic Development Quarterly. 16(3), 251272.

Ostrom, E. (1990) Governing the Commons: The Evolution of Institutions for Collective Action. Cambridge: Cambridge University Press.

Sandler, T. (1992) Collective Action: Theory and Applications. Ann Arbor: University of Michigan Press

Singleton, S. (1998) Constructing Cooperation. Ann Arbor: University of Michigan Press.

U.S. Department of Labor. (2003). Notice of Availability of Funds and Solicitation for Grant Applications (SGA) for Business-Led H-1B Technical Skills Training Grants (SGA 03114). <http://wdsc.doleta.gov/sga/sga/h-1b_grants.asp $>$ accessed February, 2004.

U.S. General Accounting Office. (2002). Workforce Investment Act: Improvements Needed in Performance Measures to Provide a More Accurate picture of WIA's Effectiveness. GAO-02-275. <http://www.gao.gov/>, accessed April, 2002.

Workforce ATM. (2003). States Participating in WRIS as of 6/6/03. <http://www. workforceatm.org/articles/printer_friendly.cfm?results_art_filemane=wrismap.htm $>$ accessed June, 2003.

Wright, D.S. (1988) Understanding Intergovernmental Relations. $\left(3^{\text {rd }}\right.$ ed.) Pacific Grove: Brooks/Cole Publishing Company.

Zimmerman, J. F. (2002) Interstate Cooperation: Compacts and Administrative Agreements./ Westport: Praeger. 
Table 1. Sector Representative on the Board

\begin{tabular}{lr}
\hline Affiliation & $\%$ of \\
\hline Business & Respondents \\
Labor Organization & 7 \\
Education Program & 13 \\
Economic Development Agency & 5 \\
One-Stop Program Partner & 15 \\
Community Based Organization & 9 \\
Public Official ${ }^{1}$ & 3 \\
Other & 3 \\
\hline Notes: & \\
1. "Public Official" includes locally elected officials and & \\
representatives of local government. & \\
2. "Other" includes representatives from the sectors of health \\
care, public policy research, agriculture or farmer, \\
community or rural issues, youth services, child support, \\
TANF or public assistance. \\
Source: Author's calculations from Workforce Investment Board Member Survey, 2003
\end{tabular}

Table 2. t-test Results and Descriptive Statistics for Variables from the IGR Literature

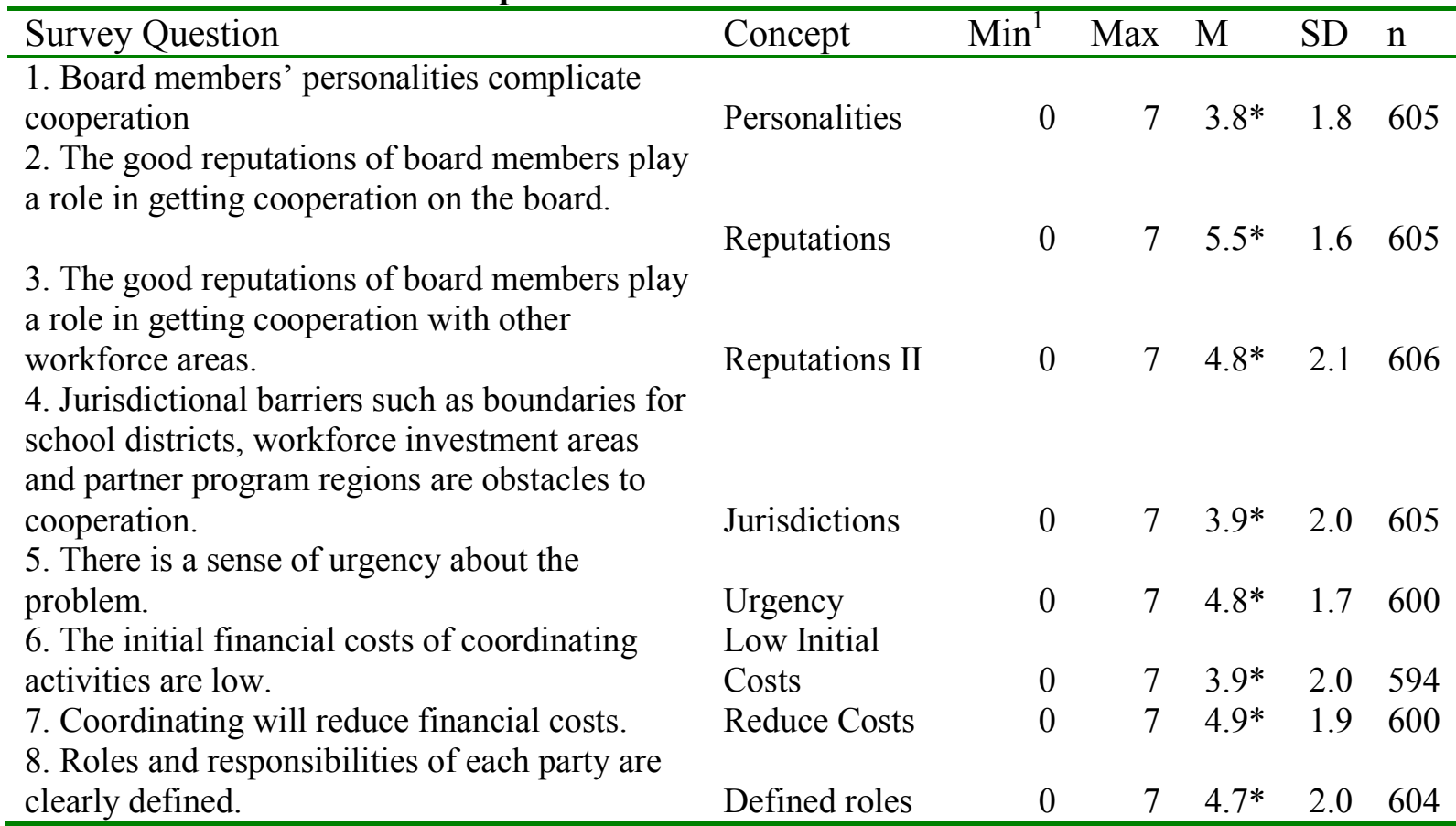

$* \mathrm{p}<.05$ Notes: 1 . Min = minimum; Max = maximum; $\mathrm{M}=$ mean; $\mathrm{SD}=$ standard deviation; all questions on scale $0-7$

Source: Author's calculations from Workforce Investment Board Member Survey, 2003 
This is an electronic version of an article published in Journal of the Community Development Society 39(4): 1-16. Journal of the Community

Development Society is available online at: http:/www.informaworld.com/smpp. DOI: 10.1080/15575330809489655

Table 3. t-test Results and Descriptive Statistics for Variables from the Collective Action Literature

\begin{tabular}{|c|c|c|c|c|c|c|}
\hline Survey Question & Concept & $\operatorname{Min}^{1}$ & Max & $\mathrm{M}$ & SD & $\mathrm{n}$ \\
\hline $\begin{array}{l}\text { 9. Cooperation makes it difficult to receive } \\
\text { appropriate credit for outcomes. (negatively } \\
\text { worded -reversed coding) }\end{array}$ & Credit & 0 & 7 & $4.8^{*}$ & 2.0 & 607 \\
\hline $\begin{array}{l}\text { 10. It takes too much time to reach goals } \\
\text { under the WIA. }\end{array}$ & Time & 0 & 7 & $4.3^{*}$ & 1.9 & 607 \\
\hline $\begin{array}{l}\text { 11. The WIA is too complicated to consider } \\
\text { cooperation with other workforce areas. } \\
12 \text {. More services can be provided because }\end{array}$ & Complexity & 0 & 7 & $3.2^{*}$ & 1.8 & 605 \\
\hline $\begin{array}{l}\text { of coordination. } \\
\text { 13. More employers will be served because }\end{array}$ & $\begin{array}{l}\text { More Services } \\
\text { More }\end{array}$ & 0 & 7 & $5.4^{*}$ & 1.7 & 600 \\
\hline $\begin{array}{l}\text { of coordination. } \\
14 \text { More individuals will be served because }\end{array}$ & $\begin{array}{l}\text { Employers } \\
\text { More }\end{array}$ & 0 & 7 & $5.5^{*}$ & 1.8 & 604 \\
\hline $\begin{array}{l}\text { of coordination. } \\
15 \text {. There is an opportunity to obtain more }\end{array}$ & $\begin{array}{l}\text { Individuals } \\
\text { More }\end{array}$ & 0 & 7 & $5.6^{*}$ & 1.7 & 603 \\
\hline $\begin{array}{l}\text { information. } \\
16 \text {. There is an opportunity to obtain more }\end{array}$ & Information & 0 & 7 & $5.4^{*}$ & 1.7 & 601 \\
\hline $\begin{array}{l}\text { grants. } \\
\text { 17. The local workforce areas that work } \\
\text { together are better off for having } \\
\text { coordinated their activities. }\end{array}$ & More Money & 0 & 7 & $4.9^{*}$ & 2.3 & 600 \\
\hline
\end{tabular}

$* \mathrm{p}<.05$ Notes: 1 . Min $=$ minimum; $\mathrm{Max}=$ maximum; $\mathrm{M}=$ Mean; $\mathrm{SD}=$ standard deviation; all questions on scale $0-7$

Source: Author's calculations from Workforce Investment Board Member Survey, 2003 
This is an electronic version of an article published in Journal of the Community Development Society 39(4): 1-16. Journal of the Community Development Society is available online at: http://www.informaworld.com/smpp. DOI: 10.1080/15575330809489655

Table 4. t-test Results and Descriptive Statistics of Measures of the way Workforce Investment Board Work

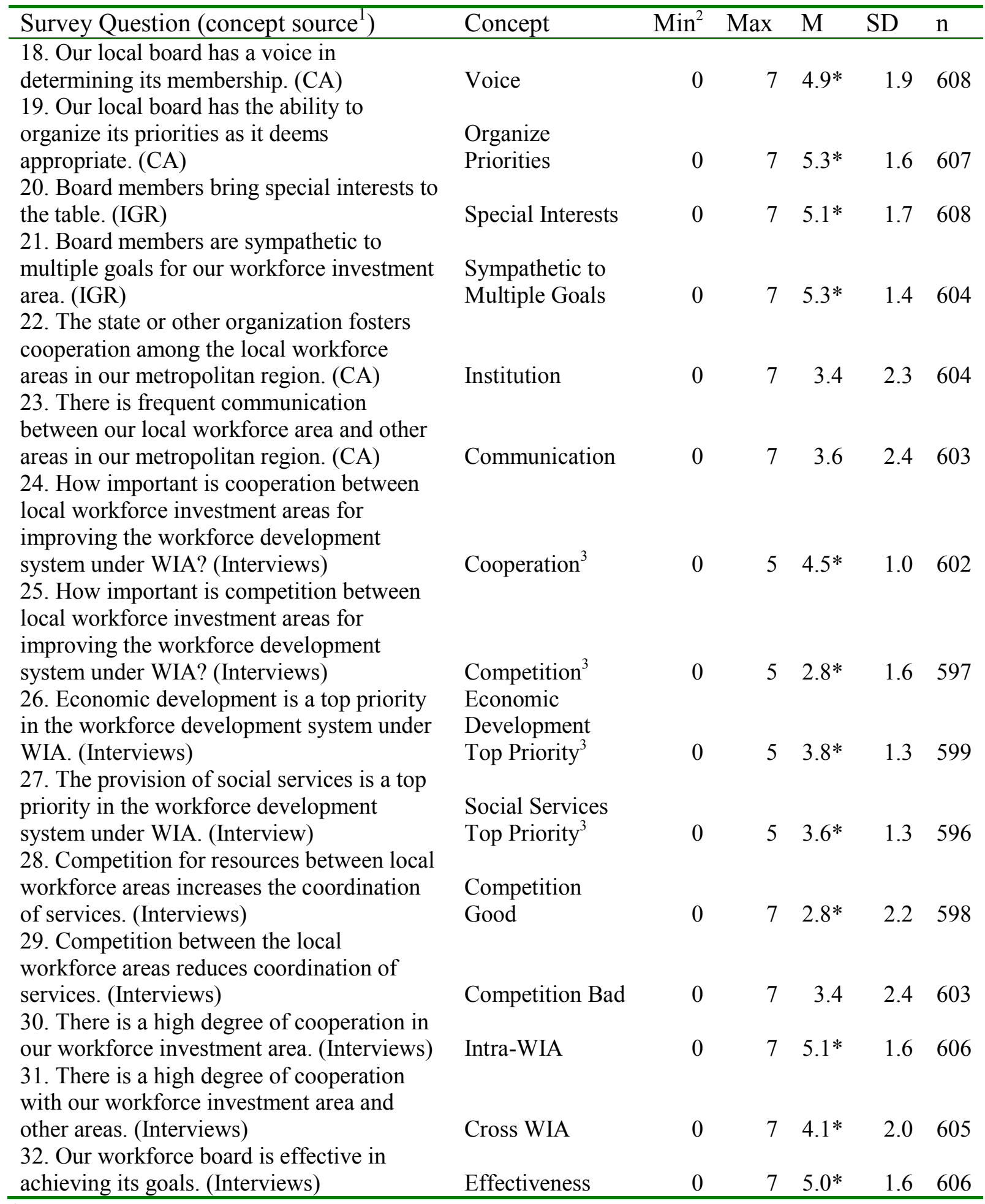

$* \mathrm{p}<.05$

Notes: 1. IGR stands for intergovernmental relations and CA stands for collective action

2. $\mathrm{Min}=$ minimum; $\mathrm{Max}=$ maximum; $\mathrm{M}=$ Mean; $\mathrm{SD}=$ standard deviation;

3. Questions on scale 0-5 all others 0-7

Source: Author's calculations from Workforce Investment Board Member Survey, 2003. 
Table 5. Factors that Differ by Type of Region

\begin{tabular}{lrll}
\hline Variable & & Intra-state & Interstate \\
\hline & $\mathrm{M}$ & 3.6 & 3.9 \\
Personalities $^{1}$ & $\mathrm{SD}$ & 1.8 & 1.8 \\
& $\mathrm{M}$ & 4.6 & 5.0 \\
Voice $^{2}$ & $\mathrm{SD}$ & 2.1 & 1.9 \\
Organizing $^{\text {Priorities }}{ }^{3}$ & $\mathrm{M}$ & 5.1 & 5.4 \\
Within WIA & $\mathrm{SD}$ & 1.3 & 1.5 \\
Cooperation $^{4}$ & $\mathrm{M}$ & 3.8 & 4.2 \\
\hline
\end{tabular}

Notes: All questions on scale $0-7$

1. $\mathrm{F}(1,604)=2.95, \mathrm{p}<.10$, Bartlett's $\chi^{2}=.69^{11}$

2. $\mathrm{F}(1,607)=4.19, \mathrm{p}<.05$, Bartlett's $\chi^{2}=.12$

3. $\mathrm{F}(1,605)=2.93, \mathrm{p}<.10$, Bartlett's $\chi^{2}=.41$

4. $\mathrm{F}(1,603)=3.60, \mathrm{p}<.10$, Bartlett's $\chi^{2}=.75$

Source: Author's calculations from Workforce Investment

Board Member Survey, 2003

Table 6. Factor Analysis of 10 IGR Concepts on Cooperation

\begin{tabular}{|c|c|c|c|}
\hline Concept & \multicolumn{3}{|c|}{ Factors } \\
\hline & $\begin{array}{l}\text { Financial } \\
\text { Costs, Roles } \\
\text { and Urgency }\end{array}$ & $\begin{array}{l}\text { Personalities } \\
\text { and Interests }\end{array}$ & Reputations \\
\hline Personalities & .00 & .63 & -.01 \\
\hline Reputations & .40 & -.10 & .49 \\
\hline Reputations II & .40 & .01 & .42 \\
\hline Jurisdictions & .15 & .43 & .05 \\
\hline Urgency & .37 & -.17 & -.31 \\
\hline Low Initial Costs & .33 & .12 & -.39 \\
\hline Reduce Costs & .38 & .01 & -.31 \\
\hline Defined roles & .39 & .03 & -.33 \\
\hline Special Interests & .13 & .53 & .21 \\
\hline Sympathetic to & & & \\
\hline Multiple Goals & .32 & .28 & .29 \\
\hline Cronbach's $\alpha$ & .59 & & \\
\hline Eigenvalues & 2.5 & 1.5 & 1.3 \\
\hline Percent of Total & & & \\
\hline Variance & 25.00 & 14.59 & 12.75 \\
\hline Total Explained & & & \\
\hline Variance $=$ & 52.34 & & \\
\hline
\end{tabular}

Note: Entries are factor coefficients from a principal component analysis with orthogonal rotation. $\mathrm{n}=565$ 
Table 7. Factor Analysis of 11 Collective Action Concepts on Cooperation

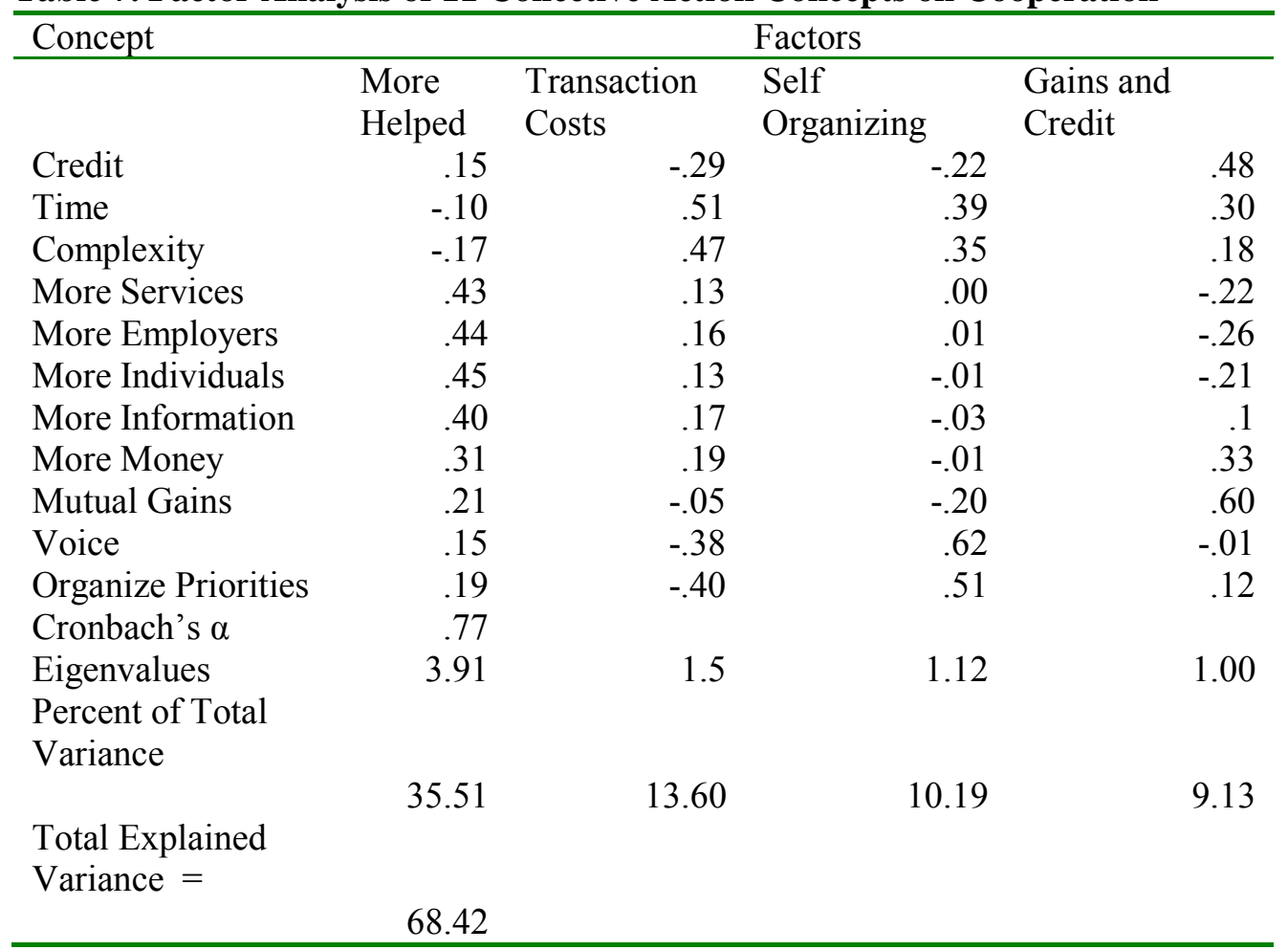

Note: Entries are factor coefficients from a principal component analysis with orthogonal rotation. $\mathrm{n}=581$ 


\section{ENDNOTES}

${ }^{1}$ Workforce Investment Board area is a designated area for implementing WIA policy.

${ }^{2}$ The seventeen mandated programs are: Adult Worker, Dislocated Worker, Youth, Wagner-Peyser Employment Service, Trade Adjustment Assistance Training, Employment and Training Services to Veterans, Unemployment Insurance, Job Corps, Welfare-to-Work, Senior Community Service Employment, Migrant \& Seasonal Farmworker Employment and Training, Native American Employment and Training, Vocational Rehabilitation Services, Adult Education and Literacy, Carl D. Perkins Vocational Education, DHHS Community Services Block Grant, and HUD-administered employment and training. Two optional programs are: Temporary Assistance for Needy Families (TANF) and Food Stamps Employment and Training program.

${ }^{3}$ Common pool resources are natural or man-made resource systems that are typically large and therefore costly to exclude people from using. Typical examples of common pool resources include fishing grounds, grazing areas, bridges, mainframe computers, and bodies of water (Ostrom,1999, p. 30).

${ }_{5}^{4}$ Italics in original

5 "One-stops" are physical locations that operate as career centers. They provide information about and access to job training, education, and employment services for employers and employees alike at a single neighborhood office.

${ }^{6}$ Interviewees were assured confidentiality and therefore are not referenced individually.

${ }^{7}$ Board member surveys were dropped from the total population if informed they were no longer on the board, passed away, or changed jobs.

${ }^{8}$ In instances where there were unequal variances on the factors between intra- and interstate regions, $\mathrm{t}$ tests for unequal variances were conducted to determine if there is statistically significant differences between the means.

${ }^{9}$ The H-1B grant is a technical skills training grant to address domestic labor shortages in high skill and high technology occupations. Its focus is on raising the technical skill levels of American workers so they can take advantage of the new technology-related employment opportunities. Fees paid by employers who bring foreign workers into the United States to work in high skill or specialty occupations on a temporary basis under H-1B nonimmigrant visas finance these grants (U.S. Department of Labor, 2003).

${ }^{10}$ A preliminary analysis using the Keiser-Meyer-Olkin (KMO) measure of sampling adequacy indicate the data are suitable for PCA. The sampling adequacy exceeds the critical value of .5 where the KMO equals .70 for the IGR concepts and .83 for the collective action concepts.

${ }^{11}$ Bartlett's $\chi^{2}$ is a formal test of the equal variances assumptions. If Bartlett's $\chi^{2}$ is statistically significant we cannot assume equal variance and cannot trust the ANOVA results. In instances where equal variance was drawn into question, two-sample t-tests for unequal variances were run. 